\section{Targeted ablation of ILK from the murine heart results in dilated cardiomyopathy and spontaneous heart failure}

\author{
Donald E. White, ${ }^{1}$ Pierre Coutu, ${ }^{2}$ Yan-Fen Shi, ${ }^{2}$ \\ Jean-Claude Tardif, ${ }^{2}$ Stanley Nattel, ${ }^{2}$ \\ René St. Arnaud, ${ }^{3}$ Shoukat Dedhar, ${ }^{4}$ \\ and William J. Muller ${ }^{1,5}$ \\ ${ }^{1}$ Department of Biochemistry and Department of Medicine, \\ McGill University, Montreal, Canada H3A 1A1; ${ }^{2}$ Montreal \\ Heart Institute, Université de Montréal, Montreal, Canada \\ H1T 1C8; ${ }^{3}$ Shriners Hospital, Montreal, Canada H3G 1A6; \\ ${ }^{4}$ Department of Biochemistry and BC Cancer Agency, \\ University of British Columbia, Vancouver, Canada V5Z 1L3
}

A requirement for integrin-mediated adhesion in cardiac physiology is revealed through targeted deletion of integrin-associated genes in the murine heart. Here we show that targeted ablation of the integrin-linked kinase (ILK) expression results in spontaneous cardiomyopathy and heart failure by 6 wk of age. Deletion of ILK results in disaggregation of cardiomyocytes, associated with disruption of adhesion signaling through the $\beta 1$-integrin/FAK (focal adhesion kinase) complex. Importantly, the loss of ILK is accompanied by a reduction in cardiac Akt phosphorylation, which normally provides a protective response against stress. Together, these results suggest that ILK plays a central role in protecting the mammalian heart against cardiomyopathy and failure.

Supplemental material is available at http://www.genesdev.org.

Received June 13, 2006; revised version accepted July 27, 2006.

Integrin-linked kinase (ILK) is a $59-\mathrm{kDa}$ protein expressed in a wide variety of mammalian cell types and tissues, including colon, mammary gland, lung, liver, heart, pancreas, skeletal muscle, chondrocytes, lymphocytes, macrophages, and platelets (Hannigan et al. 1996; Li et al. 1997; Liu et al. 2005). The prototypical human isoform of ILK was originally characterized in terms of its oncogenic properties, which were attributed to serine/threonine kinase activity localized to the $\mathrm{C}$ terminus (Hannigan et al. 1996, 2005; Persad et al. 2001; White et al. 2001). Through the phosphorylation of downstream targets such as Akt and GSK-3 $\beta$, ILK was shown to promote oncogenic transformation through the induction of anti-apoptotic pathways and cell cycle progression (Delcommenne et al. 1998; Novak et al. 1998; D'Amico et al. 2000; Persad et al. 2000; White et al. 2001).

[Keywords: Integrin-linked kinase; ILK; integrin; cardiomyopathy] ${ }^{5}$ Corresponding author.

E-MAIL William.muller@mcgill.ca; FAX (514) 843-1478.

Article is online at http://www.genesdev.org/cgi/doi/10.1101/gad.1458906.
In addition to a serine/threonine kinase domain, ILK contains structural motifs involved in protein-protein and protein-lipid interactions (Wu 2001). These domains include four tandem ankyrin repeats in the $\mathrm{N}$ terminus, which have been shown to bind the adaptor protein PINCH, a LIM-only protein that associates with the SH2/SH3-domain-containing Nck2 (Tu et al. 1999; Wu 2004, 2005). By binding molecules such as insulin receptor substrate-1 (IRS-1), DOCK180, and p21-activated kinase (PAK), the ILK/PINCH/Nck2 complex provides a bridge between receptor tyrosine kinases and the regulatory machinery of the cytoskeleton (Zhang et al. 2002). In addition, the $\mathrm{C}$ terminus of ILK has been shown to bind molecules such as paxillin, $\beta 1$ - and $\beta 3$-integrins, and CH-ILKBP/actopaxin/affixin/parvin, an actin-binding focal adhesion protein (Hannigan et al. 1996; Tu et al. 2001; Yamaji et al. 2001; Wu 2004).

The nature of these interactions suggests that ILK plays a role as a molecular scaffold, necessary for maintaining the integrity of integrin-based cell adhesion complexes. Experiments involving the genetic ablation of ILK in Drosophila and Caenorhabditis elegans, as well as in the mouse epiblast and various cell types, have, indeed, confirmed that ILK plays a critical role in linking the actin-based cytoskeleton to the plasma membrane (Yamaji et al. 2001; Zervas et al. 2001; Mackinnon et al. 2002; Sakai et al. 2003). ILK-null flies, for example, show a phenotype of impaired muscle attachment at integrincontaining adhesion sites, due to a failure to recruit and assemble actin filaments on the inner side of the cell membrane (Zervas et al. 2001; Mackinnon et al. 2002).

The phenotype resulting from loss of ILK in these organisms suggests that ILK plays a central role as a biomechanical transducer of integrin-mediated adhesion in tissues requiring mechanical force or contractility (Zervas et al. 2001; Mackinnon et al. 2002). In this regard, contractile muscle cells of the mammalian heart represent ideal candidates for a critical physiological role for ILK. An important contribution of ILK in regulating the physiology of the heart is, indeed, suggested by several lines of evidence. First, ILK is expressed abundantly in both human and mouse cardiac tissue (Hannigan et al. 1996; Li et al. 1997). Second, the ILK-induced activation of Akt promotes cardiac survival and repair downstream from thymosin $\beta 4$ following coronary artery ligation in mice (Bock-Marquette et al. 2004). Third, an ILK/ $\mathrm{PINCH} /$ parvin complex has been shown to regulate the integrin-mediated signaling pathways involved in hypertrophic and apoptotic responses of cardiomyocytes in culture (Chen et al. 2005). In addition, ILK is indirectly implicated in cardiac physiology by reports that the targeted ablation of $\beta 1$-integrin and associated molecules, including focal adhesion kinase (FAK) and melusin, results in cardiomyopathy and sudden death in response to aortic pressure overload (Shai et al. 2002; Brancaccio et al. 2003).

Despite this evidence, a physiological role for ILK in cardiac contractility has not been demonstrated. Consequently, we designed the present study to directly test the role of ILK in murine cardiac function. Using a genetargeting approach, we show that loss of ILK in the mouse heart results in dilated cardiomyopathy and sudden death. In addition, this phenotype is associated with 
a decrease in FAK phosphorylation and Akt phosphorylation, both previously shown to be important regulators of the cardiac functional response to stress. Consistent with its role in $\beta 1$-integrin-mediated adhesion complexes, the loss of ILK is accompanied by disaggregation of cardiomyocytes in vivo, and a concomitant downregulation of $\beta 1$-integrin protein. Together, these results suggest that ILK is essential for maintenance of normal cardiac function.

\section{Results and Discussion}

Tissue expression patterns and experiments with cultured cardiomyocytes suggest that ILK may play a critical role in cardiac physiology (Hannigan et al. 1996; Li et al. 1997; Chen et al. 2005). To directly test this hypothesis, we have used a conditional gene-targeting approach to ablate ILK expression in the murine heart. To accomplish this, mice harboring a conditional loxP1-flanked allele of the ilk gene (ILK ${ }^{\mathrm{fl}}$ ) (Terpstra et al. 2003; Troussard et al. 2003) were bred with a second line of mice expressing the bacteriophage CRE recombinase under transcriptional control of the muscle creatine kinase (mck) promoter (Wang et al. 1999). The mck promoter is expressed in skeletal and cardiac muscle, and has been used to generate CRE-mediated cardiac gene knockouts in previously published mouse models (Wang et al. 1999; Oudit et al. 2004). Through successive breeding of these two lines, we generated a large cohort of mice expressing the mckCRE transgene and harboring two copies of the loxP1-flanked ilk allele (mckCRE ILK ${ }^{\mathrm{fl} / \mathrm{fl}}$ ). In addition, littermate control animals representing various genetic combinations were simultaneously generated from these crosses. All mice were of the FVB/N genetic background.

CRE-mediated excision of the loxP1-flanked ilk alleles in tissues of mckCRE ILK ${ }^{\mathrm{fl} / \mathrm{fl}}$ mice was confirmed using a PCR-based protocol designed to amplify the intact and recombined forms of the loxP1-flanked allele (Supplementary Fig. 1A). Consistent with known mck promoter specificity, CRE-mediated excision of the loxP1-flanked ilk allele was found to be highly efficient in skeletal and cardiac muscle from mckCRE ILK ${ }^{\mathrm{fl} / \mathrm{fl}}$ mice (Supplementary Fig. 1A, lanes 3,4, respectively). In contrast, CRE-mediated recombination was absent in mammary gland tissue from these animals (Supplementary Fig. 1A, lane 2).

To confirm that excision of the conditional ilk allele in the hearts of mckCRE ILK ${ }^{\mathrm{fl} / \mathrm{fl}}$ mice resulted in a corresponding loss of ILK protein, we performed immunoblot analysis on cardiac tissue lysates from mckCRE $\mathrm{ILK}^{\mathrm{fl} / \mathrm{fl}}$ and control animals (Supplementary Fig. 1B). Consistent with robust excision of the loxP1-flanked ilk alleles in hearts from mckCRE ILK ${ }^{\mathrm{fl} / \mathrm{fl}}$ mice, ILK protein levels were greatly reduced in pooled cardiac tissue lysates from these animals, in contrast to those of control littermates (Supplementary Fig. 1B, top panel, cf. lanes 1 and 2). The dramatic difference in ILK levels was not due to protein loading, as Akt protein levels were comparable between the hearts of mckCRE ILK $^{\mathrm{fl} / \mathrm{fl}}$ and control mice (Supplementary Fig. 1B, bottom panel).

Given that the mckCRE transgene is expressed in both skeletal muscle and heart, we monitored a large cohort of mckCRE ILK ${ }^{\mathrm{fl} / \mathrm{fl}}$ and control animals over a period of several months for signs of distress, including muscle weakness and behavioral abnormalities such as problems with breathing, gait, or eating habits. In addition, we established that the mckCRE ILK $^{\mathrm{fl} / \mathrm{fl}}$ combination had not resulted in embryonic lethality, since all genetic combinations were born according to expected Mendelian ratios (data not shown).

Despite efficient excision of the ilk gene in skeletal muscle, there was no evidence of skeletal muscle defects, both in terms of foreleg strength and muscle histology, in the mckCRE ILK ${ }^{\mathrm{fl} / \mathrm{fl}}$ animals (data not shown). However, even though the overall behavior and size of mckCRE ILK ${ }^{\mathrm{fl} / \mathrm{fl}}$ mice were indistinguishable from control animals (data not shown), we noticed that all mice of the mckCRE ILK $^{\mathrm{fl} / \mathrm{fl}}$ background died suddenly, starting at $\sim 6 \mathrm{wk}$ of age. As a result, a cohort of mckCRE ILK ${ }^{\mathrm{fl} / \mathrm{fl}}$ animals $(n=24)$ and corresponding control littermates was monitored on a daily basis starting at the age of 4 wk. Strikingly, all mckCRE ILK ${ }^{\mathrm{fl} / \mathrm{fl}}$ animals died between $\sim 6$ and 12 wk of age, with a median age of death being 2 mo (Fig. 1A). Control littermates, in contrast, lived up to 1 yr of age with no evidence of morbidity (Fig. 1A).

During the 6-wk monitoring period, a small cohort of mckCRE ILK ${ }^{\mathrm{fl} / \mathrm{fl}}$ animals $(n=7)$ was discovered in an
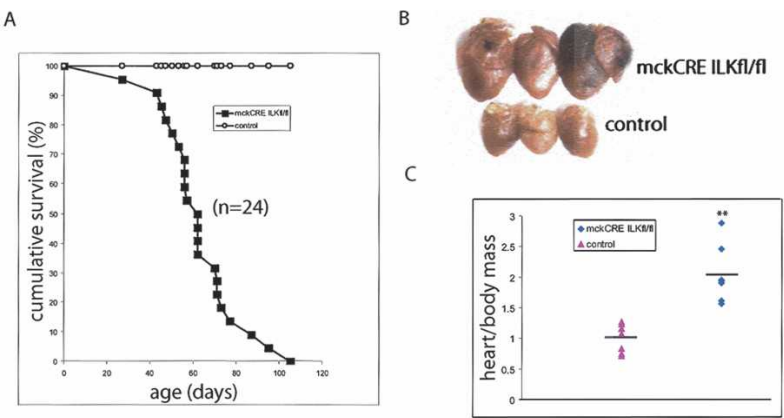

$\mathrm{E}$

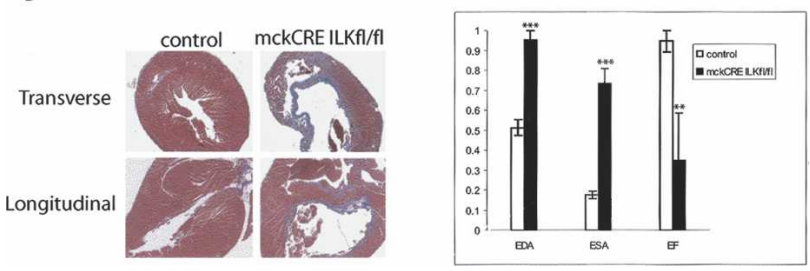

Figure 1. Left ventricular dilation and impaired contraction in ILKnull hearts. (A) Mice of the mckCRE ILK ${ }^{\mathrm{fl} / \mathrm{fl}}$ genetic combination (black squares) succumbed to sudden death between 6 and 12 wk of age (median $=8 \mathrm{wk})$. Control littermate animals are represented by open circles. $(B)$ Hearts from mckCRE ILK ${ }^{\mathrm{fl} / \mathrm{fl}}$ mice (top row) appear enlarged relative to control mice (bottom row). Hearts are representative of moribund mckCRE ILK ${ }^{\mathrm{fl} / \mathrm{fl}}$ animals. (C) Hearts from mckCRE ILK ${ }^{\mathrm{fl} / \mathrm{fl}}$ animals (blue diamonds) have an average mass twofold greater than those from control animals (pink triangles). Mass was determined for seven representative animals from mckCRE $\mathrm{ILK}^{\mathrm{fl} / \mathrm{fl}}$ and control genotypes, and is presented as a ratio to overall body mass to correct for mouse size. $(D)$ Sections of cardiac tissue were prepared from control (left panels) and mckCRE ILK ${ }^{\mathrm{fl} / \mathrm{fl}}$ (right panels) animals, and stained with trichrome stain. Samples were prepared as cross (top panels) and longitudinal (bottom panels) sections. A dilated left ventricle is visible in each section prepared from mckCRE ILK ${ }^{\mathrm{fl} / \mathrm{fl}}$ mice. (E) End diastolic (EDA) and end systolic (ESA) areas were increased in mckCRE ILK ${ }^{\mathrm{fl} / \mathrm{fl}}$ animals (black bars), relative to controls (white bars). The ejection fraction (EF) was correspondingly reduced in mckCRE ILK ${ }^{\mathrm{fl} / \mathrm{fl}}$ animals. These data are indicative of left ventricular dilation and impaired pumping capacity of hearts from mckCRE ILK ${ }^{\mathrm{fl} / \mathrm{fl}}$ mice. Error bars represent SEM. $\left.{ }^{\star \star \star}\right)$ $p<0.01,\left(^{\star \star \star}\right) p<0.001$, Student's unpaired $t$-test. 
acute phase of morbidity. This phenotype included labored breathing, lack of physical strength, disorientation, problems with balance, and a hunched, withdrawn behavior. Interestingly, these changes reflect classic human symptoms of dilated cardiomyopathy (DCM), which include shortness of breath, fatigue, light-headedness, fainting, lack of strength, and finally sudden death (Towbin and Bowles 2002). The moribund animals were sacrificed, and postmortem examinations were performed immediately. In all animals the hearts were grossly enlarged (Fig. 1B) and showed a twofold increase in the heart-to-body mass ratio (Fig. 1C). Consistent with the overall increase in size, trichrome-stained transverse and longitudinal sections of hearts from these mckCRE $\mathrm{ILK}^{\mathrm{fl} / \mathrm{fl}}$ animals revealed dramatically dilated left ventricular chambers, with evidence of fibrosis (Fig. 1D).

The acute nature of the morbidity and mortality in mckCRE ILK ${ }^{\mathrm{fl} / \mathrm{fl}}$ mice, combined with the overall dilated appearance of their hearts, suggests that the loss of ILK results in DCM. Since DCM is known to be associated with impaired cardiac function, we subjected four male mckCRE ILK ${ }^{\mathrm{fl} / \mathrm{fl}}$ and four male control animals to echocardiographic analysis. The enlarged left ventricular chamber observed in the histological sections (Fig. 1D) was found to correspond to an increase in end diastolic (EDA) and end systolic (ESA) areas, as shown in Figure 1E. Importantly, the ejection fraction (EF) was greatly reduced in the mckCRE ILK ${ }^{\mathrm{fl} / \mathrm{fl}}$ background, consistent with impaired pumping capacity of the hearts from these mice (Fig. 1E). Cardiac function, therefore, is, indeed, impaired in the mckCRE ILK ${ }^{\mathrm{fl} / \mathrm{fl}}$ mice, consistent with a phenotype of DCM.

The phenotype resulting from cardiac-specific ablation of ILK closely resembles that reported following targeted deletion of $\beta 1$-integrin, FAK, and melusin (Shai et al. 2002; Brancaccio et al. 2003; Peng et al. 2006). The similarity in the phenotype between these models is consistent with the colocalization of these proteins in $\beta 1$-integrin-containing adhesion complexes. In cardiomyocytes in particular, these proteins, including ILK, have been shown to be localized to the costameres, regions of the sarcolemma coinciding with the Z-bands of striated cardiac muscle (Chen et al. 2005). Costameres are $\beta 1$-integrin-dependent adhesion sites, and targeted deletion of $\beta 1$-integrin results in failure of the adaptive cardiac response to pressure overload (Shai et al. 2002). In addition, the critical role of $\mathrm{Z}$-band proteins in mediating the stress response of cardiomyocytes has been demonstrated for proteins such as muscle LIM protein (MLP) (Knoll et al. 2002). To confirm that ILK is expressed in the costameres of murine cardiac muscle, we performed immunofluorescence analysis on cryosections of hearts from wild-type animals. Using a polyclonal antibody directed against ILK, we, indeed, detected ILK protein in a pattern consistent with that of Z-bands and costameres of cardiomyocytes (Fig. 2A and inset).

The localization of ILK to costameric regions of murine cardiac muscle suggests a role for ILK in cardiomyocyte adhesion complexes. To study the impact of ILK ablation on the architecture and structural integrity of the heart, we therefore performed immunofluorescence analysis on frozen heart sections, using tissue obtained from mckCRE ILK ${ }^{\mathrm{fl} / \mathrm{fl}}$ mice (Fig. 2B). The absence of red staining along the sarcolemma of the myocytes confirmed that ILK had, indeed, been lost from this tissue. Strikingly, the loss of ILK resulted in disaggregation of

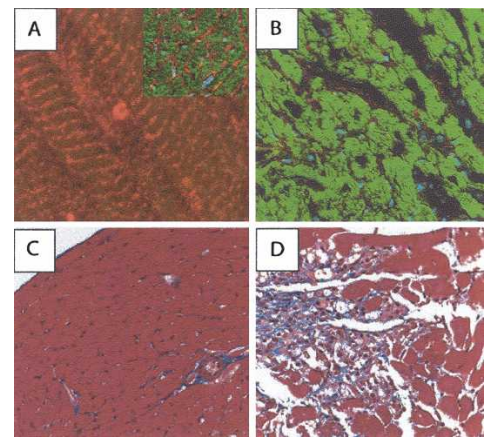

Figure 2. ILK is required for cardiac muscle integrity. (A) Frozen section of heart from a wild-type FVB mouse that was incubated with an antibody specific for ILK, followed by a Cy3-conjugated secondary antibody. Note the expression of ILK (red) in the costameric regions of the murine cardiac myocytes. Inset shows the expression pattern in a cross-section of a wild-type heart, revealing ILK expression in the sarcolemma. Phalloidin stain appears green. $(B)$ Frozen section of heart from an mckCRE ILK ${ }^{\mathrm{fl} / \mathrm{fl}}$ mouse that was subjected to the same immunostaining protocol as in $A$. Note the absence of $\mathrm{Cy} 3$ signal in the heart tissue from this animal, indicating an absence of ILK expression. Cardiomyocytes from hearts of this genotype appear disaggregated following the loss of ILK. Hearts of this genetic combination were prepared from moribund animals exhibiting a dilated phenotype. $(C, D)$ Hearts from control $(C)$ and mckCRE ILK $^{\mathrm{fl} / \mathrm{fl}}(D)$ mice were sectioned and stained with trichrome stain. Note again the disaggregated tissue in the mckCRE ILK $^{\mathrm{fl} / \mathrm{fl}}$ genotype, in addition to large amounts of interstitial fibrosis (blue stain).

adjacent cardiomyocytes within the heart tissue (Fig. 2B). In addition, cardiac tissue from control and mckCRE $\mathrm{ILK}^{\mathrm{fl} / \mathrm{fl}}$ animals was subjected to trichrome staining to permit more accurate examination of the tissue architecture (Fig. 2C,D). Examination of the trichromestained sections confirmed dramatic disaggregation of cardiac tissue in mckCRE ILK ${ }^{\mathrm{fl} / \mathrm{fl}}$ animals, compared with the compact arrangement of cardiomyocytes in control mice. In addition to a loss of structural integrity, trichrome staining revealed an accumulation of interstitial fibrotic tissue in hearts from mckCRE ILK ${ }^{\mathrm{fl} / \mathrm{fl}}$ mice (Fig. 2D).

Since $\beta 1$-integrin and FAK cardiac knockout models suffered pressure-induced cardiomyopathy similar to the DCM observed in the mckCRE ILK ${ }^{\mathrm{fl} / \mathrm{fl}}$ animals, we decided to check the status of $\beta 1$-integrin and FAK in the hearts of mckCRE ILK ${ }^{\mathrm{fl} / \mathrm{fl}}$ mice by immunoblot analysis (Fig. 3). For this purpose, we prepared pooled cardiac protein lysates from mckCRE ILK ${ }^{\mathrm{fl} / \mathrm{fl}}$ mice displaying a moribund phenotype and harboring dilated hearts, as well as from young (4- to 5-wk-old) healthy mckCRE $\mathrm{ILK}^{\mathrm{fl} / \mathrm{fl}}$ animals not yet exhibiting a dilated cardiac phenotype. In addition, pooled lysates were prepared from littermate control animals. Probing of the lysates with an anti- $\beta 1$-integrin monoclonal antibody revealed a reduction of total $\beta 1$-integrin protein levels in phenotypically abnormal hearts from moribund mckCRE ILK ${ }^{\mathrm{fl} / \mathrm{fl}}$ mice (Fig. 3A, top panel, cf. lane 3 and control sample in lane 1). Interestingly, total $\beta 1$-integrin protein levels were also reduced in morphologically and histologically normal hearts from younger, healthy mckCRE ILK ${ }^{\mathrm{fl} / \mathrm{fl}}$ mice (Fig. 3A, top panel, lane 2). A reprobing of the membrane was performed with an anti-ILK polyclonal antibody to confirm that ILK had been ablated in the hearts of these animals (Fig. 3A, bottom panel). The reduction in $\beta 1$-integrin protein levels in pre-DCM hearts, as well 


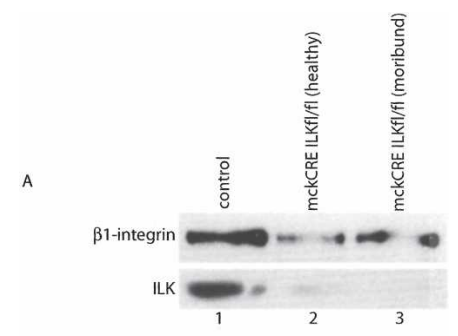

B

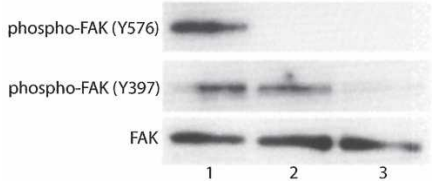

Figure 3. Loss of ILK impacts $\beta 1$-integrin/FAK signaling in mckCRE $\mathrm{ILK}^{\mathrm{fl} / \mathrm{fl}}$ mice. (A) Pooled protein lysates from control (lane 1) and mckCRE ILK $^{\mathrm{fl} / \mathrm{fl}}$ (lanes 2,3) mice were subjected to immunoblot analysis, by probing with antibodies to $\beta 1$-integrin (top panel) and ILK (bottom panel). Mice of the mckCRE ILK ${ }^{\mathrm{fl} / \mathrm{fl}}$ genotype were selected at two time points: young, healthy animals not yet exhibiting evidence of cardiomyopathy (lane 2) and older mice showing evidence of morbidity due to cardiac failure (lane 3). Note that loss of ILK protein is accompanied by a corresponding reduction in $\beta 1$ integrin protein levels. $(B)$ Pooled lysates from $A$ were subjected to immunoblot analysis for levels of FAK phospho-Tyr 576 (top panel) and phospho-Tyr 379 (bottom panel).

as in diseased hearts, suggests that the down-regulation of $\beta 1$-integrin in hearts of $\mathrm{mckCRE}$ ILK $^{\mathrm{fl} / \mathrm{fl}}$ mice may be due to ILK ablation directly, rather than indirectly to DCM-related consequences. Regardless of the mechanism, this result is consistent with an established role for $\beta 1$-integrin in maintaining cardiac integrity.

Since FAK kinase activity also plays an important role downstream of $\beta 1$-integrin and is required for protection against pressure-induced DCM (Peng et al. 2006), we probed the same set of protein lysates with antibodies directed against two major phosphorylation sites on the FAK molecule (Fig. 3B). Using an antibody specific for phospho-Tyr 576 in the kinase domain of FAK, we found that phosphorylation of this residue was not induced in the ILK-null hearts of mckCRE ILK ${ }^{\mathrm{fl} / \mathrm{fl}}$ mice (Fig. 3B, top panel, cf. lanes 2,3 and the control sample in lane 1). Phosphorylation of this residue normally occurs after FAK is recruited to $\beta 1$-integrin-containing adhesion complexes, and is required for activation of FAK kinase activity. These results are therefore consistent with disruption of $\beta 1$-integrin-dependent adhesion signaling in hearts of mckCRE ILK $^{\mathrm{fl} / \mathrm{fl}}$ animals, and may explain in part the DCM phenotype in these mice.

When the lysates were probed with an antibody directed against phosphotyrosine residue 397 in the amino portion of FAK, we found that a decrease in phosphorylation occurred only in hearts exhibiting DCM, and not in pre-DCM hearts from mckCRE ILK ${ }^{\mathrm{f} / \mathrm{fl}}$ animals (Fig. $3 \mathrm{~B}$, middle panel, cf. lanes 2 and 3). This phosphotyrosine residue represents the binding site for major effectors of cell adhesion, such as the c-Src kinase and PI3' kinase. These results therefore suggest residual maintenance of the FAK-containing adhesion complexes in preDCM hearts, even though FAK kinase activity has been dramatically reduced. As expected from the dramatic disaggregation of cardiac tissue in moribund mckCRE
ILK $^{\mathrm{fl} / \mathrm{fl}}$ animals, the onset of DCM coincides with inhibition of FAK phosphorylation on this second residue. The loss of ILK therefore results in a progressive disruption of the $\beta 1$-integrin/FAK adhesion signaling complex, which may play an important role in the onset of DCM in mckCRE ILK ${ }^{\mathrm{fl} / \mathrm{fl}}$ mice.

As expected, hearts from healthy mckCRE ILK ${ }^{\mathrm{fl} / \mathrm{fl}}$ mice appeared normal in terms of size and histology (data not shown). However, since all mice of this genotype failed to survive beyond 12 wk of age, we hypothesized that the dilated cardiac phenotype and subsequent death represented a failed response to normal physiological stresses. The spontaneous death of mckCRE ILK ${ }^{\mathrm{fl} / \mathrm{fl}}$ mice, starting at $\sim 6 \mathrm{wk}$ of age, is in contrast to other models involving cardiac-specific ablation of $\beta 1$-integrin-related proteins, such as melusin and FAK (Brancaccio et al. 2003; Peng et al. 2006). In the case of these models, a progressive change in cardiac physiology, from hypertrophy to DCM occurs in response to artificially applied aortic pressure overload, with little or no evidence of spontaneous heart failure (Brancaccio et al. 2003; Peng et al. 2006). In the model involving cardiacspecific FAK inactivation, evidence of spontaneous DCM did not appear until 9 mo of age. The mckCRE $\mathrm{ILK}^{\mathrm{fl} / \mathrm{fl}}$ mice, however, die at a relatively early age $/ \mathrm{me}$ dian age $=2 \mathrm{mo}$ ), and in the absence of externally applied stresses.

The relatively rapid decline in cardiac function in mckCRE ILK ${ }^{\mathrm{fl} / \mathrm{fl}}$ mice would therefore suggest that ILK plays a critical role in protecting the heart from normal physiological stress. Indeed, the sensitivity of ILK-null hearts was apparent by the fact that the mckCRE ILK ${ }^{\mathrm{fl} / \mathrm{fl}}$ mice often died during mating and during attempted surgical procedures such as implantation of telemetry devices (data not shown). We were able to detect evidence of cardiac stress at the molecular level by performing immunoblot analysis on the pooled lysates from control and mckCRE ILK ${ }^{\mathrm{fl} / \mathrm{fl}}$ animals, using antibodies directed against phospho-ERK1/2 (Fig. 4A). The status of ERK1/2 phosphorylation was chosen as an indicator of cardiac stress in the mckCRE ILK ${ }^{\mathrm{fl} / \mathrm{fl}}$ model due to previously published reports that ERK $1 / 2$ phosphorylation provides a protective response in the mammalian heart (Wang and Proud 2002; Proud 2004). By probing cardiac protein lysates with an antibody recognizing the phosphorylated form of ERK1/2, we found that ERK1/2 phosphorylation was elevated in hearts of moribund mckCRE ILK ${ }^{\mathrm{fl} / \mathrm{fl}}$ animals showing DCM (Fig. 4A, lane 3), as well as in hearts from young, healthy mckCRE ILK ${ }^{\mathrm{fl} / \mathrm{fl}}$ mice not yet showing phenotypic evidence of cardiomyopathy (Fig. 4A, lane 2). This result demonstrates that hearts from mckCRE ILK ${ }^{\mathrm{fl} / \mathrm{fl}}$ mice show evidence of stress at the molecular level prior to phenotypic changes at the histological and physiological levels.

In addition to ERK1/2, Akt represents another important regulator of cardiac stress (Proud 2004). The role of Akt in promoting cardiac survival is related to the induction of protein synthesis and cardiac hypertrophy, which facilitates a compensatory increase in pumping capacity. Since Akt phosphorylation at Ser 473 has been shown to be regulated downstream from ILK kinase activity (Delcommenne et al. 1998), we examined the status of Akt phosphorylation in hearts of mckCRE ILK ${ }^{\mathrm{fl} / \mathrm{fl}}$ mice (Fig. 4B). In contrast to elevated levels of ERK $1 / 2$ phosphorylation in the hearts of mckCRE ILK ${ }^{\mathrm{fl} / \mathrm{fl}}$ mice, levels of phospho-Ser 473 of Akt are dramatically re- 


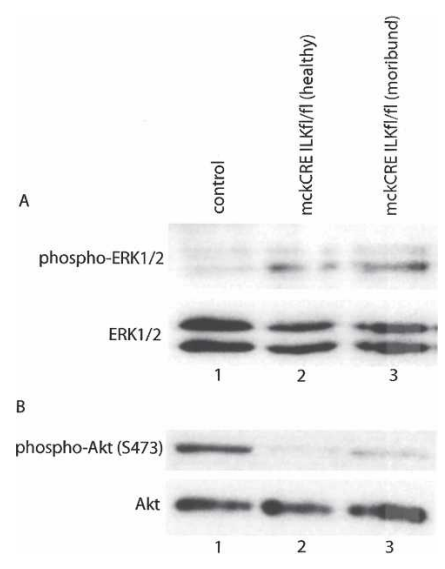

Figure 4. Loss of ILK in murine hearts results in impaired molecular stress response. (A, top panel) Pooled cardiac protein lysates from control (lane 1) and mckCRE ILK ${ }^{\mathrm{fl} / \mathrm{fl}}$ animals (lanes 2,3) were probed for phospho-ERK1/2 levels. mckCRE ILK ${ }^{\mathrm{fl} / \mathrm{fl}}$ mice were chosen at a young, healthy stage (lane 2) and an older moribund stage (lane 3). Bottom panel shows levels of total ERK1/2 protein. Elevated levels of phosphor-ERK1/2 reflect a molecular response to cardiac stress. ( $B$, top panel) Lysates from $A$ were subjected to immunoblot analysis for levels of Akt phospho-Tyr 473. Bottom panel shows total Akt protein levels. Note the reduction in Akt phosphorylation, which normally provides a protective role by promoting hypertrophy during cardiac stress.

duced in response to ILK ablation (Fig. 4B, top panel). This result is consistent with the published role for ILK in the induction of Akt phosphorylation (Delcommenne et al. 1998). More importantly, the inhibition of Akt phosphorylation in hearts of mckCRE ILK ${ }^{\mathrm{fl} / \mathrm{fl}}$ animals indirectly suggests that there may be an impaired stress response in the ILK-null hearts. Since Akt is important for protein synthesis and cardiac hypertrophy in response to increased load on the heart (Proud 2004), the inhibition of Akt phosphorylation in ILK-null hearts may explain the rapid induction of DCM and sudden death in mckCRE ILK ${ }^{\mathrm{fl} / \mathrm{fl}}$ mice. In conclusion, the phenotype of mckCRE ILK ${ }^{\mathrm{fl} / \mathrm{fl}}$ mice provides a direct demonstration that ILK plays a critical role in the maintenance of mammalian cardiac physiology. Given the unique cardiac phenotype exhibited by these transgenic mice, these mice may prove to be a useful model to test the efficacy of cardiac stem cell therapies. In addition, the mckCRE ILK ${ }^{\mathrm{fl} l / f 1}$ mice represent an excellent model to confirm the role that ILK plays downstream from thymosin $\beta 4$ in promoting cardiac survival and repair following coronary artery ligation (Bock-Marquette et al. 2004).

\section{Materials and methods}

Generation of mckCRE ILK ${ }^{f l f f}$ mice

The generation of mice harboring a conditional loxP1-flanked allele of ILK has been described previously (Terpstra et al. 2003; Troussard et al. 2003). These mice were crossed with animals expressing the mckCRE transgene (Wang et al. 1999) to generate mckCRE ILK ${ }^{\mathrm{f} / \mathrm{fl}}$ mice. Both strains were backcrossed into the $\mathrm{FVB} / \mathrm{N}$ background prior to breeding. Mice were housed in the Animal Resource Center of the Royal Victoria Hospital. Animals undergoing echocardiographic analysis were housed at the Montreal Heart Institute, Université de Montréal. All mice were housed and treated according to CCAC guidelines.

PCR analysis of CRE-mediated excision

Total genomic DNA was prepared from cardiac and skeletal muscle and mammary gland tissue using a standard protocol. PCR primer sequences and amplification parameters were described elsewhere (Terpstra et al. 2003; Troussard et al. 2003).

Echocardiographic analysis

Area and M mode echocardiographic measurements were performed in anesthetized (isofluorane) mice using a Hewlett-Packard Sonos 5500 and S-12 transducer. The ejection fraction was estimated as $\mathrm{EF}=(\mathrm{EDA}-\mathrm{ESA}) /$ $\mathrm{EDA} \times 100 \%$, where EDA and ESA are the end diastolic and systolic areas, respectively.

Immunofluorescence and trichrome staining

For immunofluorescence analysis, 8-um cryosections were prepared from flash-frozen cardiac tissue. Sections were incubated for $1 \mathrm{~h}$ with anti-ILK polyclonal antibody (Upstate Biotechnology 06-592) at a dilution of 1:100, followed by $1 \mathrm{~h}$ with anti-rabbit Cy3-conjugated secondary antibody (1:1000). Sections were counterstained with DAPI (blue) and Phalloidin (green). For trichrome staining of cardiac tissue, hearts were fixed in buffered formalin and embedded in paraffin. Sections $(8 \mu \mathrm{m})$ were then stained with trichrome according to the manufacturer's instructions.

Statistical analysis

Data were presented as mean \pm SEM. Statistical significance was calculated using the Student's unpaired $t$-test.

\section{Acknowledgments}

We thank Cynthia Lavoie and Vasilios Papavasiliou for help with animal care and transport. W.J.M. is a recipient of a CRC Chair in Molecular Oncology. This work was funded by the Canadian Institutes of Health Research.

\section{References}

Bock-Marquette, I., Saxena, A., White, M.D., Dimaio, J.M., and Srivastava, D. 2004. Thymosin $\beta 4$ activates integrin-linked kinase and promotes cardiac cell migration, survival and cardiac repair. Nature 432: 466-472.

Brancaccio, M., Fratta, L., Notte, A., Hirsch, E., Poulet, R., Guazzone, S., De Acetis, M., Vecchione, C., Marino, G., Altruda, F., et al. 2003. Melusin, a muscle-specific integrin $\beta 1$-interacting protein, is required to prevent cardiac failure in response to chronic pressure overload. Nat. Med. 9: 68-75.

Chen, H., Huang, X.N., Yan, W., Chen, K., Guo, L., Tummalapali, L., Dedhar, S., St-Arnaud, R., Wu, C., and Sepulveda, J.L. 2005. Role of the integrin-linked kinase/PINCH1/ $\alpha$-parvin complex in cardiac myocyte hypertrophy. Lab. Invest. 85: 1342-1356.

D'Amico, M., Hulit, J., Amanatullah, D.F., Zafonte, B.T., Albanese, C., Bouzahzah, B., Fu, M., Augenlicht, L.H., Donehower, L.A., Takemaru, K., et al. 2000. The integrin-linked kinase regulates the cyclin D1 gene through glycogen synthase kinase $3 \beta$ and cAMP-responsive element-binding protein-dependent pathways. J. Biol. Chem. 275: 32649-32657.

Delcommenne, M., Tan, C., Gray, V., Rue, L., Woodgett, J., and Dedhar, S. 1998. Phosphoinositide-3-OH kinase-dependent regulation of glycogen synthase kinase 3 and protein kinase B/AKT by the integrinlinked kinase. Proc. Nat1. Acad. Sci. 95: 11211-11216.

Hannigan, G.E., Leung-Hagesteijn, C., Fitz-Gibbon, L., Coppolino, M.G., Radeva, G., Filmus, J., Bell, J.C., and Dedhar, S. 1996. Regulation of cell adhesion and anchorage-dependent growth by a new $\beta$ 1-integrinlinked protein kinase. Nature 379: 91-96.

Hannigan, G., Troussard, A.A., and Dedhar, S. 2005. Integrin-linked kinase: A cancer therapeutic target unique among its ILK. Nat. Rev. Cancer 5: 51-63.

Knoll, R., Hoshijima, M., Hoffman, H.M., Person, V., Lorenzen-Schmidt, I., Bang, M.L., Hayashi, T., Shiga, N., Yasukawa, H., Schaper, W., et al. 2002. The cardiac mechanical stretch sensor machinery involves a $\mathrm{Z}$ disc complex that is defective in a subset of human dilated cardiomyopathy. Cell 111: 943-955.

Li, F., Liu, J., Mayne, R., and Wu, C. 1997. Identification and characterization of a mouse protein kinase that is highly homologous to human integrin-linked kinase. Biochim. Biophys. Acta 1358: 215-220.

Liu, E., Sinha, S., Williams, C., Cyrille, M., Heller, E., Snapper, S.B., 
Georgopoulos, K., St-Arnaud, R., Force, T., Dedhar, S., et al. 2005. Targeted deletion of integrin-linked kinase reveals a role in T-cell chemotaxis and survival. Mol. Cell. Biol. 25: 11145-11155.

Mackinnon, A.C., Qadota, H., Norman, K.R., Moerman, D.G., and Williams, B.D. 2002. C. elegans PAT-4/ILK functions as an adaptor protein within integrin adhesion complexes. Curr. Biol. 12: 787-797.

Novak, A., Hsu, S.C., Leung-Hagesteijn, C., Radeva, G., Papkoff, J., Montesano, R., Roskelley, C., Grosschedl, R., and Dedhar, S. 1998. Cell adhesion and the integrin-linked kinase regulate the LEF-1 and ß-catenin signaling pathways. Proc. Nat1. Acad. Sci. 95: 4374-4379.

Oudit, G.Y., Sun, H., Kerfant, B.G., Crackower, M.A., Penninger, J.M. and Backx, P.H. 2004. The role of phosphoinositide-3 kinase and PTEN in cardiovascular physiology and disease. J. Mol. Cell. Cardiol. 37: 449-471.

Peng, X., Kraus, M.S., Wei, H., Shen, T.L., Pariaut, R., Alcaraz, A., Ji, G., Cheng, L., Yang, Q., Kotlikoff, M.I., et al. 2006. Inactivation of focal adhesion kinase in cardiomyocytes promotes eccentric cardiac hypertrophy and fibrosis in mice. J. Clin. Invest. 116: 217-227.

Persad, S., Attwell, S., Gray, V., Delcommenne, M., Troussard, A., Sanghera, J., and Dedhar, S. 2000. Inhibition of integrin-linked kinase (ILK) suppresses activation of protein kinase B/Akt and induces cell cycle arrest and apoptosis of PTEN-mutant prostate cancer cells. Proc. Natl. Acad. Sci. 97: 3207-3212.

Persad, S., Attwell, S., Gray, V., Mawji, N., Deng, J.T., Leung, D., Yan, J., Sanghera, J., Walsh, M.P., and Dedhar, S. 2001. Regulation of protein kinase B/Akt-serine 473 phosphorylation by integrin-linked kinase: Critical roles for kinase activity and amino acids arginine 211 and serine 343. J. Biol. Chem. 276: 27462-27469.

Proud, C.G. 2004. Ras, PI3-kinase and mTOR signaling in cardiac hypertrophy. Cardiovasc. Res. 63: 403-413.

Sakai, T., Li, S., Docheva, D., Grashoff, C., Sakai, K., Kostka, G., Braun, A., Pfeifer, A., Yurchenco, P.D., and Fassler, R. 2003. Integrin-linked kinase (ILK) is required for polarizing the epiblast, cell adhesion, and controlling actin accumulation. Genes \& Dev. 17: 926-940.

Shai, S.Y., Harpf, A.E., Babbitt, C.J., Jordan, M.C., Fishbein, M.C., Chen, J., Omura, M., Leil, T.A., Becker, K.D., Jiang, M., et al. 2002. Cardiac myocyte-specific excision of the $\beta 1$ integrin gene results in myocardial fibrosis and cardiac failure. Circ. Res. 90: 458-464.

Terpstra, L., Prud'homme, J., Arabian, A., Takeda, S., Karsenty, G., Dedhar, S., and St-Arnaud, R. 2003. Reduced chondrocyte proliferation and chondrodysplasia in mice lacking the integrin-linked kinase in chondrocytes. J. Cell Biol. 162: 139-148.

Towbin, J.A. and Bowles, N.E. 2002. The failing heart. Nature 415: 227233.

Troussard, A.A., Mawji, N.M., Ong, C., Mui, A., St-Arnaud, R., and Dedhar, S. 2003. Conditional knock-out of integrin-linked kinase demonstrates an essential role in protein kinase B/Akt activation. J. Biol. Chem. 278: 22374-22378.

Tu, Y., Li, F., Goicoechea, S., and Wu, C. 1999. The LIM-only protein PINCH directly interacts with integrin-linked kinase and is recruited to integrin-rich sites in spreading cells. Mol. Cell. Biol. 19: 24252434.

Tu, Y., Huang, Y., Zhang, Y., Hua, Y., and Wu, C. 2001. A new focal adhesion protein that interacts with integrin-linked kinase and regulates cell adhesion and spreading. J. Cell Biol. 153: 585-598.

Wang, L. and Proud, C.G. 2002. Ras/Erk signaling is essential for activation of protein synthesis by Gq protein-coupled receptor agonists in adult cardiomyocytes. Circ. Res. 91: 821-829.

Wang, I., Wilhelmsson, H., Graff, C., Li, H., Oldfors, A., Rustin, P., Bruning, J.C., Kahn, C.R., Clayton, D.A., Barsh, G.S., et al. 1999. Dilated cardiomyopathy and atrioventricular conduction blocks induced by heart-specific inactivation of mitochondrial DNA gene expression. Nat. Genet. 21: 133-137.

White, D.E., Cardiff, R.D., Dedhar, S., and Muller, W.J. 2001. Mammary epithelial-specific expression of the integrin-linked kinase (ILK) results in the induction of mammary gland hyperplasias and tumors in transgenic mice. Oncogene 20: 7064-7072.

Wu, C. 2001. ILK interactions. J. Cell Sci. 114: 2549-2550.

. 2004. The PINCH-ILK-parvin complexes: Assembly, functions and regulation. Biochim. Biophys. Acta 1692: 55-62.

2005. PINCH, $\mathrm{N}(\mathrm{i}) \mathrm{ck}$ and the ILK: Network wiring at cell-matrix adhesions. Trends Cell Biol. 15: 460-466.

Yamaji, S., Suzuki, A., Sugiyama, Y., Koide, Y., Yoshida, M., Kanamori,
H., Mohri, H., Ohno, S., and Ishigatsubo, Y. 2001. A novel integrinlinked kinase-binding protein, affixin, is involved in the early stage of cell-substrate interaction. J. Cell Biol. 153: 1251-1264.

Zervas, C.G., Gregory, S.L., and Brown, N.H. 2001. Drosophila integrinlinked kinase is required at sites of integrin adhesion to link the cytoskeleton to the plasma membrane. J. Cell Biol. 152: 1007-1018.

Zhang, Y., Guo, L., Chen, K., and Wu, C. 2002. A critical role of the PINCH-integrin-linked kinase interaction in the regulation of cell shape change and migration. J. Biol. Chem. 277: 318-326. 


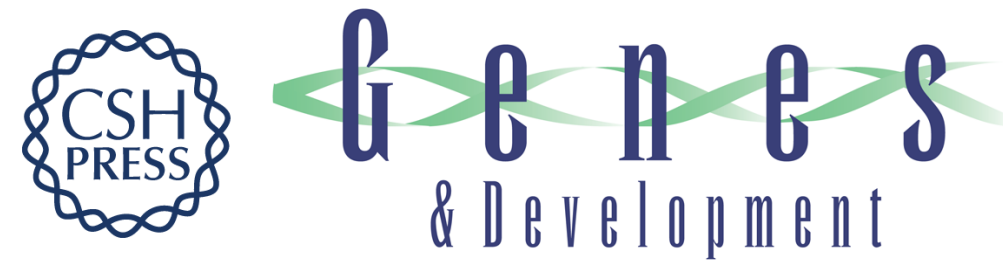

\section{Targeted ablation of ILK from the murine heart results in dilated cardiomyopathy and spontaneous heart failure}

Donald E. White, Pierre Coutu, Yan-Fen Shi, et al.

Genes Dev. 2006, 20:

Access the most recent version at doi:10.1101/gad.1458906

Supplemental http://genesdev.cshlp.org/content/suppl/2006/09/05/20.17.2355.DC1
Material

References This article cites 33 articles, 17 of which can be accessed free at:

http://genesdev.cshlp.org/content/20/17/2355.full.html\#ref-list-1

License

Email Alerting

Receive free email alerts when new articles cite this article - sign up in the box at the top

Service

right corner of the article or click here.

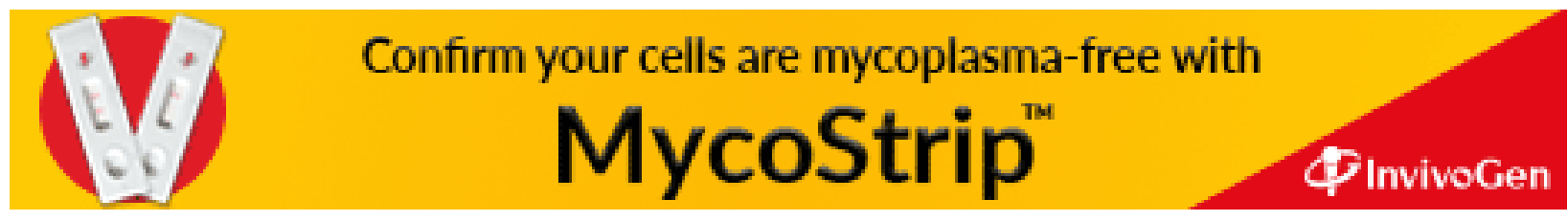

